\title{
EL CINE SIN ENCUADRE: PROPUESTA DE ESCALA DE IMPLICACIÓN NARRATIVA EN REALIDAD VIRTUAL
}

Frameless Cinema: Proposal for a Narrative Implication Scale for virtual reality

O cinema sem enquadramento: proposta de Escala de Implicação Narrativa em realidade virtual

Diego Bonilla, California State University, Sacramento (Estados Unidos)

diego@csus.edu

Helena Galán Fajardo, Universidad Carlos III de Madrid (España)

egalan@hum.uc3m.es

Recibido: 19 de septiembre de 2019

Aprobado: 16 de diciembre de 2019

Fecha de prepublicación: 14 de julio de 2020 


\title{
DISERTACIONES
}

\section{ESTUDIOS}

Estudios sobre imágenes en el nuevo ecosistema mediático

ISSN: $1856-9536$

Doi: https://doi.org/10.12804/revistas.urosario.edu.co/disertaciones/a.8252

Volumen 13, Número 2 / Julio-diciembre 2020

Versión PDF para imprimir desde

http://revistas.urosario.edu.co/index.php/disertaciones

\section{RESUMEN}

La posibilidad de grabar en $360^{\circ}$ ha despertado el interés de emprendedores e investigadores en torno a las potenciales facultades narrativas de la realidad virtual en distintos ámbitos. No obstante, aún quedan algunas cuestiones que no han sido lo suficientemente confirmadas, como el mayor nivel de implicación narrativa del espectador en esta nueva forma de narrar. Para suplir esa carencia, esta investigación presenta el diseño de un análisis experimental planteado en distintas fases. Se trata de un proyecto piloto de tipo cuantitativo-cualitativo basado en la escala mneq (Busselle \& Bilandzic, 2009) que permite evaluar y comparar la experiencia de visionado de un relato narrativo mediante presentación en realidad virtual y diferentes tipos de pantallas bidimensionales a un mínimo de 100 personas divididas en grupos experimentales. Bajo el supuesto de que cada tratamiento o cada tecnología (variable independiente) tiene diferentes impactos en la implicación narrativa (variable dependiente) del espectador, se pretende analizar la empatía (ep), simpatía (s), toma de perspectiva cognitiva (cp), pérdida de tiempo (lt), pérdida de auto- conciencia (ls), presencia narrativa (np), participación narrativa (ni), distracción (d), facilidad de acceso cognitivo (ec) y realismo narrativo (nr). Para ello se incluyen cuatro tipos de análisis diferentes (estadístico, de varianza, de observación, de preguntas abiertas). Ofrecemos un nuevo modelo de análisis de elaboración propia para obras de realidad virtual cinematográficas completas en español. El diseño experimental busca establecer un modelo de investigación integral con el fin de debatir si la realidad virtual ofrece, como se cree, mayor envolvimiento (engagement).

Palabras clave: realidad virtual, cine en $360^{\circ}$, identificación espectatorial, engagement, encuadre.

\begin{abstract}
The ability to record in $360^{\circ}$ has sparked interest among entrepreneurs and researchers regarding the potential narrative powers of virtual reality in different fields. However, there are still some issues that have not been sufficiently addressed such as the higher level of narrative involvement of viewers in this new form of narration. To fill this gap, this study presents the design of an experimental analysis performed in different phases. It is a quantitativequalitative pilot project based on the mneq scale (Busselle \& Bilandzic, 2009) that is used to evaluate and compare the experience of viewing a narrative story through virtual reality and different types of two-dimensional screens for a minimum of 100 people divided into experimental groups. Under the assumption that each treatment or technology (independent variable) has different impacts on the viewer's narrative involvement (dependent variable), the objective is to analyze empathy, sympathy, cognitive perspective, loss of time, loss of self-awareness, narrative presence, narrative involvement, distraction, ease of cognitive access, and narrative realism. To do so, four different types of analysis are included (statistical, variance, observation, open-ended questions). We offer a self-developed novel analysis model for full cinematographic virtual reality works in Spanish. The experimental design seeks to establish a comprehensive research model to debate whether virtual reality offers more engagement, as is believed.
\end{abstract}

Keywords: Virtual reality, $360^{\circ}$ cinema, spectatorial identification, engagement, framing. 


\section{DISERTACIONES}

\section{ESTUDIOS}

Estudios sobre imágenes en el nuevo ecosistema mediático

ISSN: $1856-9536$

Doi: https://doi.org/10.12804/revistas.urosario.edu.co/disertaciones/a.8252

Volumen 13, Número 2 / Julio-diciembre 2020

Versión PDF para imprimir desde

http://revistas.urosario.edu.co/index.php/disertaciones

\section{RESUMO}

A possibilidade de gravar em $360^{\circ}$ tem despertado o interesse de empreendedores e pesquisadores em torno das potenciais faculdades narrativas da realidade virtual em distintos âmbitos. No entanto, ainda ficam algumas questões que não têm sido o suficientemente confirmadas, como o maior nível de implicação narrativa do espectador nesta nova forma de narrar. Para suprir essa carência, esta pesquisa apresenta o desenho de uma análise experimental apresentado em diferentes fases. Trata-se de um projeto piloto de tipo quantitativo-qualitativo baseado na escala mneq (Busselle \& Bilandzic, 2009) que permite avaliar e comparar a experiência de visionado de um relato narrativo mediante apresentação em realidade virtual e diferentes tipos de ecrãs bidimensionais a um m 'nimo de 100 pessoas divididas em grupos experimentais. Sob o suposto de que cada tratamento ou cada tecnologia (variável independente) tem diferentes impactos na implicação narrativa (variável dependente) do espectador, pretende-se analisar a empatia (ep) simpatia (s), tomada de perspectiva cognitiva (cp), perda de tempo (lt), perda de auto- consciência (ls), presença narrativa (np), participação narrativa (ni), distração (d), facilidade de acesso cognitivo (ec) e realismo narrativo (nr). Para isso se incluem quatro tipos de análises diferentes (estatístico, de variância, de observação, de perguntas abertas). Oferecemos um novo modelo de análise de elaboração própria para obras de realidade virtual cinematográficas completas em espanhol. O desenho experimental busca estabelecer um modelo de pesquisa integral com o objetivo de debater se a realidade virtual oferece, como se acredita, maior envolvimento (engagement).

Palavras-chave: realidade virtual, cinema em $360^{\circ}$, identificação do espectador, engagement, enquadramento.

La invención de las pantallas y gafas de realidad virtual (Rv), así como el acceso a cámaras de video de $360^{\circ}$ ha despertado el interés en realizadores e investigadores en torno a las potenciales facultades narrativas de esta tecnología. Aunque las investigaciones al respecto son todavía recientes, con la mejora y el abaratamiento de los equipos y con el entendimiento de su funcionamiento se irá logrando mayor aceptación del público.

Si bien ha habido un desarrollo notable, la mayor parte de los proyectos comerciales de rvc han ido dirigidos a empresas de moda, turismo, deportes, y los proyectos narrativos de ficción que no han superado por regla general los seis o siete minutos están en una etapa incipiente y aún quedan muchas preguntas en el aire. Algunos autores como Kjær, Lillelund, Moth-Poulsen, Nilsson, Nordahl y Serafin (2017) han comenzado a plantearse si los enfoques tradicionales de la cinematografía se pueden aplicar directamente a la realidad virtual cinematográfica (RVc) o ello implica un cambio sustancial en la forma de narrar, sobre todo centrándose en la influencia de la frecuencia de corte en la edición y la capacidad de los espectadores para seguir la historia. 


\section{DISERTACIONES}

En este artículo se presenta el diseño de un proyecto de investigación piloto, mediante el cual se busca hacer contribuciones significativas al lenguaje narrativo de la realidad virtual y a la comprensión de sus aportaciones y limitaciones. Así mismo, se analiza, dentro del marco de la ecología de los medios, el impacto de estos sobre las personas, y se hace foco en el nivel de implicación y participación de los espectadores en el universo diegético propuesto.

\section{Antecedentes: el lenguaje de la Realidad Virtual Cinematográfica (Rvc)}

Mateer (2017) ubica el comienzo de las investigaciones en torno a la realidad virtual en el artículo de Sutherland (1968) que lleva por nombre: "A head-mounted three-dimensional display"1. Desde entonces, la velocidad y el bajo costo de los procesadores han logrado que esta penetre en el mercado de los consumidores de dos formas predominantes: basándose en gráficos generados por ordenador y en procesos de muestreo. En ambos, la experiencia se ha llevado a cabo por medio del uso de visores montados frente a los ojos del espectador/usuario y sujetos a su cabeza. De este modo, se reemplaza la visión de la realidad por un ambiente sintético (Mateer, 2017), lo cual produce la ilusión visual de estar presente físicamente en el ambiente generado por el ordenador. El usuario tiene la habilidad de mirar en cualquier dirección y la información visual es generada en tiempo real.

Así mismo, este tipo de realidad virtual presenta diferentes características respecto a la realidad virtual basada en procesos de muestreo. Por ejemplo, una imagen generada por vectores está basada en ecuaciones y procesos matemáticos, lo cual permite, entre otras cosas, incrementar el tamaño de la imagen al infinito sin perder resolución. Por el contrario, las imágenes que se obtienen mediante procesos de muestreo de luz están limitadas por el número de muestras que se tomen inicialmente, pero la calidad del color, muestra por muestra, va a ser muy alta, lo cual provee a la imagen de tonos realistas. Este tipo de características también se pueden encontrar en la reproducción de música por medio del ordenador, las notas generadas mediante una interface mIDI, y la reproducción de música capturada por medio de un proceso de muestreo de sonido. Ambas tienen ventajas y desventajas, pero la música capturada por procesos de muestreo provee de una reproducción más realista. Por último, estas diferencias también han estado presentes en la realización cinematográfica mediante modelos tridimensionales generados por ordenador y a través de procesos de muestreo (píxeles por imagen, imágenes por segundo y frecuencia de muestreo por segundo para el caso de sonido). En ese sentido, los módelos generados por computadora permiten la adecuación de múltiples elementos expresivos durante la producción (encuadre, luces, texturas, ambientes, movimiento de cámara, etc.), aunque aún es muy difícil reproducir fielmente a un humano.

Al igual que en los ejemplos anteriores, el cine convencional ${ }^{2}$ está limitado al contenido capturado por medio de procesos de muestreo, pero la calidad de reproducción de un actor humano y de un ambiente físico es muy alta. Sin embargo, reduce la mirada del espectador a un campo de posibilidades delimitadas por el encuadre. La realidad virtual cinematográfica (Rvc), basada en procesos de muestreo, presenta la limitación de ofrecer solo el punto

1 "Un monitor tridimensional montado en la cabeza" (traducción de los autores).

2 Entendido como cine con encuadre. 


\section{DISERTACIONES}

ESTUDIOS

Estudios sobre imágenes en el nuevo ecosistema mediático

ISSN: $1856-9536$

Doi: https://doi.org/10.12804/revistas.urosario.edu.co/disertaciones/a.8252

Volumen 13, Número 2 / Julio-diciembre 2020

Versión PDF para imprimir desde

http://revistas.urosario.edu.co/index.php/disertaciones

de vista utilizado en el momento de grabación, pero provee de una reproducción más realista de actores humanos y espacios físicos. Como medio de comunicación audiovisual, al igual que el cine de ficción y el cine documental tradicional (esto es, no en vR), puede ser utilizado para narrar historias.

\section{Cambios narrativos en el cine de realidad virtual en $360^{\circ}$}

El modelo de representación institucional (MRI) -concepto tomado del realizador, crítico e historiador de cine Noël Burch en Praxis du cinéma (1969) - consiste en una serie de convenciones o normas estandarizadas que se adoptan a comienzos del siglo xx, codificando el lenguaje cinematográfico con el fin de que el mundo ficcional propuesto ofrezca coherencia interna, causalidad lineal, realismo psicológico y continuidad espacial y temporal. A su vez, el montaje se entiende, en sentido amplio, como "la operación destinada a organizar el conjunto de planos que conforman un film en función de un orden prefijado. Se trata, por tanto, de un principio organizativo que rige la estructuración interna de los elementos fílmicos visuales y/o sonoros" (Zunzunegui, 1998, p. 161).

Como ha subrayado Gubern (citado en Zunzunegui, 1998, p. 161),

La operación sintagmática del montaje (selección y ordenación de fragmentos espacio/temporales) reproduce las condiciones de selectividad de la percepción y memoria humanas, en lo que éstas tienen de discontinuas y de privilegiar ciertos aspectos significativos en detrimento de otros que no lo son [...] por eso no es de extrañar que el montaje aparezca ligado desde el principio a la narratividad.

Si bien el montaje es el constructor de sentido de la pieza, en el caso del cine en $360^{\circ}$ se ofrece la posibilidad de seleccionar la direccionalidad de la mirada que, aunque no se puede controlar, sí puede definirse. Esa casualidad interna produce una relación de causa-efecto en la mente del receptor. Por eso, cuando se habla de tipos de plano en el MRI, se hace referencia a las diferentes posibilidades de enmarcar la mirada. El plano condiciona el encuadre, esto es, los límites de la imagen, lo que queda fuera y dentro del cuadro. Por eso, a diferencia de la Rvc, permite experimentar diferentes experiencias estéticas y, no solo eso, sino también proporcionar diferentes construcciones de sentido. Por ejemplo, mientras el plano general facilita información sobre el contexto o ambiente donde la narración tiene lugar, el primerísimo primer plano proporciona un acercamiento íntimo y emocional a los personajes del relato. En el caso de la Rvc, es común que el plano sea constante, ya que no existe un encuadre o, en otras palabras, el campo visual del usuario es muy amplio y no varía, como sucedería en un proceso natural de percepción. En el mRI la forma de mirar viene impuesta por la planificación (tipo y escala de los planos, distancia, duración, etc.) mientras que, en la realidad virtual, al no existir un encuadre que delimite la puesta en escena, el marco de interpretaciones es aparentemente más libre, algo que, como otras premisas, aún está por confirmar.

Como consecuencia, la falta de un encuadre despoja al creador de su habilidad para determinar qué se debe ver en cada momento. Cuando se le ofrece al usuario la ilusión de estar dentro del espacio físico de la historia, se pierde la habilidad de comunicar elementos importantes de la narración, ya que es posible que mientras el foco se pone en un personaje u objeto dentro del cuadro, la mirada esté orientada hacia otra dirección y el espectador no lo vea. La decisión de hacia dónde mirar es personal, lo que provoca que se pueda visualizar la misma obra muchas veces de forma diferente.

Esta ausencia de encuadre también va a afectar a la articulación espacio-temporal. A pesar de que los acontecimientos del relato en sí tenga una duración determinada (tiempo real), el tiempo fílmico, diferente al tiempo 


\section{DISERTACIONES}

ESTUDIOS

Estudios sobre imágenes en el nuevo ecosistema mediático

ISSN: $1856-9536$

Doi: https://doi.org/10.12804/revistas.urosario.edu.co/disertaciones/a.8252

Volumen 13, Número 2 / Julio-diciembre 2020

Versión PDF para imprimir desde

http://revistas.urosario.edu.co/index.php/disertaciones

real en cuanto implica manipulación o constructividad, cambiaría en este caso en cada espectador (tiempo de recepción). Si bien esta focalización se puede ir dirigiendo por elementos internos del propio relato, el hecho de no venir delimitada implicará una mayor diferencia entre el tiempo de visionado de unos espectadores y otros.

Por otro lado, se supone que con la realidad inmersiva el espectador debería involucrarse más en el universo de ficción propuesto, sin embargo, la experiencia ha indicado hasta ahora que no es así, sobre todo en aquellos proyectos donde el espectador se presupone dentro de la diégesis, es decir, ocupando el punto de vista de un personaje dentro del universo diegético y adoptando la posición de la cámara en un punto de vista subjetivo. Sin embargo, esta decisión, en caso del cine $360^{\circ}$ desvela, hoy por hoy (al verse la sombra de la cámara), el artificio narrativo y tecnológico, además de generar un distanciamiento por la falta de identificación con el personaje que mira.

La manera en que se construye la identificación espectatorial no es algo nuevo, pues existen algunos experimentos al respecto desde el siglo pasado. La película La dama del lago - dirigida por Robert Montgomery (1947) y adaptada de la novela del mismo título de Raymond Chandler - se rodó usando la técnica de la cámara subjetiva. Lo que se pretendía es que la cámara simulase ser uno de los personajes, en este caso el detective, Philip Marlowe. Se rodó en su totalidad en cámara subjetiva, menos unos cortes en los que el propio director le habla directamente al espectador aclarando ciertos puntos de la historia. Sin embargo, si bien la propuesta y el riesgo asumido por el director en esa época son loables, la historia resulta bastante confusa y el recurso, repetitivo.

¿Cómo podemos explicar este ejemplo y por qué lo usamos a la hora de hablar de realidad virtual? Porque hay una estrecha relación en los procesos. Al intentar involucrar al espectador en el universo de ficción tomando el lugar de la cámara, el espectador no consigue ver el rostro del detective, es decir, del personaje, con lo cual la identificación no funciona. No existe el sujeto de la mirada, solo la campo visual en plano subjetivo Incluso, cuando se emplea la focalización interna, es necesario mostrar desde una focalización externa escenas que el personaje no podría estar viendo desde la posición en la que se encuentra, pero que el espectador justifica y necesita para poder integrar la experiencia.

En la escena de The Godfather Part I (Francis Ford Coppola, 1972), que transcurre en el hospital, Michael, hermano de Sonny, va a visitar a su padre que está gravemente herido. Pronto se da cuenta de que Don Vito está desprotegido cuando se suponía que debía estar vigilado, pues el capitán de policía ha echado a los guardaespaldas. Todo ello lo vemos desde el punto de vista subjetivo de Michael (sus ojos ocuparían el lugar de la cámara). No sucede lo mismo en toda la escena. Por momentos, a pesar de tratarse de una focalización interna del personaje, se muestran acciones y espacios (el asesino subiendo las escaleras, imágenes de los pasillos) que, por la ubicación del este, no alcanzaría a ver. Sin embargo, a pesar de este falseamiento, se produce un efecto de identificación con el protagonista y con la escena, sintiendo que se ve lo que él ve. Es decir, siendo en el proceso de construcción de la mirada menos fieles al punto de vista del personaje como en La dama del lago, donde todo transcurre mediante focalización interna y plano subjetivo, la identificación espectatorial es mayor.

Lo anterior viene demostrando que los procesos de identificación en el cine son complejos. La focalización no se refiere tanto a la importancia otorgada a la mirada de un personaje, como al proceso mediante el cual se construye la mirada del espectador y su grado de conocimiento respecto a los acontecimientos y personajes. Tal y como se recoge en el libro El cine según Hitchcock (Truffaut, 2010, pp. 73-77), si un personaje está sentado en una mesa, ignora que debajo de esta hay una bomba, el espectador tiene la perspectiva necesaria para poder "ver la bomba" en la narración de los acontecimientos, por lo que su conocimiento será superior al de los personajes que 


\section{DISERTACIONES}

se representan en la obra, y esto será lo que genere el suspenso. Sin embargo, si desconociese este hecho, es decir, si su conocimiento fuese inferior, entonces descubriría lo sucedido mediante una emoción de sorpresa.

Por eso, lo habitual en los relatos audiovisuales será encontrarse con una focalización interna variable, pues con frecuencia se articulan en torno a las peripecias de un protagonista, pero no se reducen a él como canal de información, pues suele haber personajes ayudantes o antagonistas que también sirven como canales u otros focos de la información narrativa.

La explicación anterior pretende reflexionar sobre el hecho de que la inmersión en el universo de ficción no siempre es igual a una mayor identificación o mayor efecto de realidad. Este es un interesante punto de partida para abordar la narratividad en los relatos de realidad virtual, así como el proceso de identificación del espectador con los acontecimientos y personajes.

Lo anterior hace pensar que quizás el hecho de grabar mediante tecnología $360^{\circ}$ y con ausencia de encuadre no tiene que suponer necesariamente más identificación con el universo representado ni una mayor participación, como de entrada se podría intuir. Hay muchas variables tecnológicas, narrativas y psicológicas que pueden influir al respecto. En cualquier caso, son aspectos aún por investigar y que se tratarán de abordar más adelante.

\section{Limitaciones y aportaciones tecnológicas de la Realidad Virtual}

El cine en $360^{\circ}$, a nivel tecnológico, exige escenas más largas debido al reconocimiento del entorno donde se ubica la acción, así como una mayor redundancia de la información importante, previendo la dispersión del espectador.

Ya que no hay encuadre ni es fácil emplear cortes intra-escena, en el video de $360^{\circ}$ ya no son válidas las maneras tradicionales de manipular la información para crear suspense o dirigir la mirada del espectador (tales como planos detalle para resaltar un dato). Esto parecería alejarlo de ciertos tipos de thrillers o melodramas complejos, si bien se pueden generar relatos de suspenso a través de un cierto control de la direccionalidad de la mirada.

Por otro lado, la dificultad de los cortes favorece planos más largos. Así mismo, se complican los primeros planos (por la distorsión de los lentes a corta distancia), y se hace necesaria una mínima separación entre cámara y los actores, por lo cual resulta más difícil dirigir la atención del espectador hacia el área donde se quiere que mire. Entonces existe la opción de intentar manipularle para que mire donde el realizador quiere, o de respetar su libertad y armar un relato con múltiples posibilidades de fruición en determinados momentos, considerando incluso la opción de que cada persona, viendo el mismo material, perciba una historia distinta.

El $360^{\circ}$ ofrece la oportunidad de llevar audiencias masivas a instancias narrativas que actualmente resultan difíciles: trabajar ritmos más "lentos", dejar fluir los elementos con mayor libertad, darle mayor importancia a lo sensorial y lo físico, lo cual puede generar una mayor identificación con la audiencia.

Respecto al lugar del espectador o la construcción del punto de vista espectatorial, como se adelantó, en un contexto de profundas mutaciones en el campo audiovisual es preciso redefinir al espectador real como sujeto que encarna hoy nuevas funciones y ocupa espacios variados en el conjunto de la producción cultural.

Cuando se realiza una grabación con un encuadre determinado, todo el espacio afuera del cuadro puede ser utilizado. Es decir, el fuera de campo puede pasar a formar parte del campo visible si el espectador así lo estima oportuno durante el visionado, posibilidad que no existe en el cine al que estamos acostumbrados, donde el fuera de campo como mucho puede ser imaginado, pero no visto, generando otros efectos en el espectador. No obs- 


\section{DISERTACIONES}

ESTUDIOS

tante, en ambos el fuera de campo puede ser activado por la dirección de la mirada de los personajes, los efectos de sonido, etc. marcando hacia dónde se debe dirigir para no perder el control totalmente sobre la narración. Sin embargo, los recursos para generar efectos durante la grabación se limitan considerablemente, también debido a que cualquier artefacto tecnológico utilizado durante el rodaje podría verse en cualquier momento al existir un campo de $360^{\circ}$ completamente visible.

En el caso del audio de la Rvc, a diferencia del teatro, este puede ser realista o hiperrealista como lo es en el cine y, en el caso de la imagen, también puede suceder lo mismo por medio de procesos de colorización. A favor estaría la habilidad de mirar en cualquier dirección en cualquier momento, pero la falta de un encuadre hace que la Rvc sea una experiencia única. Ding, Zhou y Fung (2018) encontraron que la Rvc tiene la capacidad de generar en los usuarios emociones más fuertes; si bien es probable que este aspecto emocional apoye el falso supuesto como se adelantaba anteriormente, la sensación de inmersión en el universo diegético provee de una mayor identificación en términos psicológicos y una sensación de mayor involucración dentro de la historia. Debido a lo anterior, resulta necesario la creación de herramientas y análisis que permitan evaluar estos principios, para no partir de suposiciones sino de premisas validadas. En ese sentido, esta investigación pretende determinar de forma experimental cuál es el efecto de diferentes tecnologías para visualizar la implicación, empatía e identificación de los espectadores a la hora de adentrarse en un relato de estas características y con esta tecnología.

\section{Metodología: Modelo y herramientas de evaluación para obras realizadas en realidad virtual}

Este proyecto tiene el objetivo principal de contribuir al desarrollo de la realidad virtual como medio narrativo. En específico, interesa la utilización de la escala MNEQ (Busselle \& Bilandzic, 2009) para evaluar y comparar la experiencia de visionado de un relato narrativo en diferentes tipos de rvc y cine tradicional. Aunque existen otras investigaciones posteriores (Appel, Gnambs, Richter \& Green, 2015), se parte del trabajo de Busselle y Bilandzic (2009) porque, al margen de ser previo en cuanto a fecha, se hace foco en el instrumento validado.

De acuerdo con lo anterior, la Escala de Implicación Narrativa -compromiso/implicación emocional- resultante (tabla 1), será aplicada para determinar diferencias entre los diversos tratamientos. Esto coadyuva a determinar la validez y confiabilidad de este instrumento evaluativo, se puede fomentar su uso en estudios más amplios en el ámbito de las narrativas audiovisuales, en general, y de las narrativas en realidad virtual, en específico.

La metodología a utilizar consta de dos fases y herramientas de análisis: en la primera, se utiliza el Cuestionario para la Medición de la Implicación Narrativa, (Measuring Narrative Engagement Questionnaire, MNEQ, por sus siglas en inglés) desarrollado por Busselle y Bilandzic (2009). Aunque fue pensado inicialmente para narrativas audiovisuales en formato bidimensional, ya se había utilizado anteriormente para evaluar relatos en realidad virtual. La utilización de este cuestionario, adaptado al objeto de análisis, tiene objetivos específicos:

1. Ofrecer una valoración más de la validez y la confiabilidad del MNEQ como mecanismo de evaluación narrativa para obras de realidad virtual. 


\section{DISERTACIONES}

\section{ESTUDIOS}

Estudios sobre imágenes en el nuevo ecosistema mediático

ISSN: $1856-9536$

Doi: https://doi.org/10.12804/revistas.urosario.edu.co/disertaciones/a.8252

Volumen 13, Número 2 / Julio-diciembre 2020

Versión PDF para imprimir desde

http://revistas.urosario.edu.co/index.php/disertaciones

2. Permitir, mediante el uso del MNEQ en español, hacer un análisis comparativo de esta herramienta de evaluación en dos idiomas diferentes. Ofrecer una versión del cuestionario en español, inexistente hasta el momento.

El cuestionario, como se adelantaba, se basa en las categorías establecidas por Busselle y Bilandzic (2009), de su escala Measuring Narrative Engagement, donde van generando diversas preguntas alrededor de las siguientes variables: empatía (EP), simpatía (S), toma de perspectiva cognitiva (CP), pérdida de tiempo (LT), pérdida de autoconciencia (LS), presencia narrativa (NP), participación narrativa (NI), distracción (D), facilidad de acceso cognitivo (EC) y realismo narrativo (NR).

Un componente negativo de la interacción es la distracción. Los elementos dentro de la historia también pueden desviar la atención de la comprensión. Estos pueden ser una falla en la trama, un comportamiento que es inconsistente con las motivaciones de un personaje, o un retrato que es inconsistente con el conocimiento del mundo real o las convenciones de género. Se supone que observar casos de inconsistencia (falta de realismo o verosimilitud) durante una experiencia narrativa interferirá con el compromiso en la historia.

Algunos autores han trabajado también en el concepto de transportación que, de alguna manera, recoge también los anteriores y que puede definirse como: "Perder la noción del tiempo, no observar los eventos que ocurren a su alrededor y sentir que están completamente inmersos en el mundo de la narrativa” (Green, 2004, p. 247). La pérdida de la autoconciencia combinada con la construcción de un mundo alternativo proporciona un mecanismo explicativo para el sentido de presencia narrativa o ser en ese mundo de ficción. Requiere procesos de percepción y toma de perspectiva. Como el flujo implica que un proceso, se convierte en automático y las acciones y cogniciones únicas no requieren una deliberación consciente, los espectadores comprometidos no deben percibir dificultades en el procesamiento de la historia, sino que deben sentir que es fácil mantener el enfoque en la historia. Esto también representa una dimensión del compromiso narrativo denominado facilidad de acceso cognitivo, un concepto asociado con las experiencias de lectura (Appel, Koch, Schreier \& Groeben, 2002).

Por otro lado, se ha encontrado que el transporte está altamente relacionado con el disfrute (Bilandzic \& Busselle, 2006; Green, Brock \& Kaufman, 2004), al igual que el flujo (Csikszentmihalyi, 1991; Sherry, 2004).

A partir de estos ítems y del concepto de Engagement o implicación narrativa, seleccionamos de la escala establecida por Busselle y Bilandzic (2009), aquellos acordes a los objetivos de la investigación recogidos anteriormente. 


\section{DISERTACIONES}

ESTUDIOS

Estudios sobre imágenes en el nuevo ecosistema mediático

ISSN: $1856-9536$

Doi: https://doi.org/10.12804/revistas.urosario.edu.co/disertaciones/a. 8252

Volumen 13, Número 2 / Julio-diciembre 2020

Versión PDF para imprimir desde

http://revistas.urosario.edu.co/index.php/disertaciones

Tabla 1. Cuestionario de la Escala de Implicación Narrativa

Narrative Engagement Scale

EP3: During the program, when a main character succeeded, I felt happy, and when they suffered in some way, I felt sad. (Adapted from Cohen, 2001)

EP5: The story affected me emotionally. (Green \& Brock, 2000)

S1: I felt sorry for some of the characters in the program.

CP4: My understanding of the characters is unclear. (Adapted, Cohen, 2001)

NP1: At times during the program, the story world was closer to me than the real world. (Adapted from Kim \& Biocca, 1997)

NP3: The program created a new world, and then that world suddenly disappeared when the program ended. (Adapted from Kim \& Biocca, 1997)

NP4: During the program, my body was in the room, but my mind was inside the world created by the story. (Adapted from Kim \& Biocca, 1997)

D1: I found my mind wandering while the program was on. (-) (Green \& Brock, 2000)

D2: While the program was on I found myself thinking about other things. (-) (Appel et al., 2002)

D3: I had a hard time keeping my mind on the program. (-)

EC2: I had a hard time recognizing the thread of the story. (-) (Appel et al., 2002)

NR4: At points, I had a hard time making sense of what was going on in the program. (-)

\section{Escala de Implicación Narrativa}

EP3: Durante el cortometraje, sentí felicidad cuando los personajes parecían estar bien y tristeza cuando parecían estar mal.

EP5: La historia me afectó emocionalmente.

S1: Me sentí mal por los personajes en la historia.

CP4: Mi entendimiento de los personajes no es claro (a) (- $)^{3}$

NP1: En momentos del cortometraje, me sentí más cerca al mundo de la historia que al mundo real.

NP3: El cortometraje creó un nuevo mundo, y después ese mundo desapareció cuando el cortometraje terminó

NP4: Durante el cortometraje, mi cuerpo estaba en el cuarto, pero mi mente estaba dentro del mundo creado por la historia.

D1: Me encontré divagando durante el cortometraje. (-)

D2: Durante el programa, me encontré pensando sobre otras cosas. (-)

D3: Me costó trabajo mantenerme concentrado. (-)

EC2: Me costó trabajo entender el hilo de la historia. (-)

NR4: En ciertos momentos, me costó trabajo hacer sentido de lo que estaba ocurriendo en el cortometraje. (-)

Fuente: elaboración propia a partir del Modelo Measuring Narrative Engagement (Busselle \&

$$
\text { Bilandzic, 2009, pp. 8-10). }
$$

En la segunda fase, aún por desarrollar, se incluirá la producción de una obra narrativa ficcional que tome en consideración las necesidades del diseño experimental, de tal manera que logre homogeneizar varias partes de la experiencia narrativa y permita hacer comparaciones entre tecnologías visuales con un alto nivel de validez y con las siguientes implementaciones:

3 Preguntas con el símbolo (-) están invertidas. Traducción al español por los autores. 


\section{DISERTACIONES}

\section{ESTUDIOS}

1. Por un lado, en lugar de presentar un contenido creado para un medio hegemónico, la idea y producción de la obra ficcional considera que esta tendrá dos formas de presentación narrativa: realidad virtual y pantalla bidimensional; $y$, por otro, los procesos de decisión buscarán favorecer a ambos a la vez.

2. Para el análisis experimental contará con la creación de un cortometraje de ficción con presentación en realidad virtual y pantalla bidimensional, que permitirá realizar comparaciones en el MNEQ con mayor nivel de validez. Aunque en una de estas versiones el usuario podrá mirar en cualquier dirección y, en la otra versión, el encuadre estará determinado por un editor profesional, ambas obras van a tener exactamente el mismo audio y la misma secuencia de eventos.

3. Si bien el énfasis se centra en comparar la realidad virtual y la pantalla bidimensional (la ausencia y la presencia del encuadre), el diseño experimental cubre un rango diverso de plataformas, actualmente disponible al público.

- Visores de Realidad virtual (archivo MP4 o YouTube).

- Móvil con giroscopio (YouTube o Facebook).

- Presentación bidimensional con interactividad (YouTube o Facebook).

- Presentación bidimensional (televisión).

- Presentación bidimensional social (cine).

En lo que se refiere a la utilización de la realidad virtual cinematográfica para la experiencia de narrativas ficcionales, Keshavarz, Hecht y Lawson (2014) mencionan que en el momento de su estudio no fue posible acceder a las narrativas completas construidas para la realidad virtual. Con el fin de suplir esta carencia, en este experimento se desarrollará la producción de una narrativa audiovisual completa, considerando dos formas principales de presentación: Rvc ( 3 formas de presentación, visores, móvil y computador) y presentación bidimensional ( 2 formas de presentación, televisión y cine). El proceso de investigación incluye la realización de una historia en RVC para proveer de una experiencia narrativa compleja, con diálogos intrincados y coyunturas dramáticas, que permitan una comparación válida de la implicación narrativa (a través del MNEQ) entre las cinco diferentes formas de presentación (ver figura 1). 


\section{DISERTACIONES}

ESTUDIOS

Estudios sobre imágenes en el nuevo ecosistema mediático

ISSN: $1856-9536$

Doi: https://doi.org/10.12804/revistas.urosario.edu.co/disertaciones/a.8252

Volumen 13, Número 2 / Julio-diciembre 2020

Versión PDF para imprimir desde

http://revistas.urosario.edu.co/index.php/disertaciones

\begin{tabular}{|c|c|c|c|c|}
\hline $\begin{array}{c}\text { Visores } \\
\text { Video } 360^{\circ} \\
\text { Realidad virtual } \\
\text { Audífonos } \\
\text { Individual }\end{array}$ & $\begin{array}{c}\text { Móvil } \\
\text { Video } 360^{\circ} \\
\text { Pantalla Móvil } \\
\text { Audífonos } \\
\text { Individual }\end{array}$ & $\begin{array}{c}\text { Monitor } \\
\text { Video } 360^{\circ} \\
\text { Pantalla fija } \\
\text { Audífonos } \\
\text { Individual }\end{array}$ & $\begin{array}{l}\text { Televisión } \\
\text { Encuadre fijo } \\
\text { Pantalla fija } \\
\text { Audífonos } \\
\text { Individual }^{4}\end{array}$ & $\begin{array}{c}\text { Cine } \\
\text { Encuadre fijo } \\
\text { Pantalla fija } \\
\text { Bocinas } \\
\text { Social }\end{array}$ \\
\hline 6 & 10 & 0 & $7=0$ & 1 \\
\hline
\end{tabular}

Figura 1. Grupos experimentales basados en el tipo de experiencia de la obra

Fuente: elaboración propia.

Con la intención de centrar el análisis comparativo en solo una dimensión, la visual, en los cuatro tratamientos donde la experiencia es individual, se utilizarán el mismo tipo de audífonos para la recepción del audio de la historia. Aunque el enfoque de la investigación son las diferencias entre la realidad virtual cinematográfica y el cine normal, se han incluido otros 3 tratamientos por su popularidad y por su disponibilidad. Los sujetos en el tratamiento de realidad virtual cinematográfica utilizarán visores Oculus Go y los sujetos en el tratamiento con el móvil utilizarán dispositivos Pixel 3. Servicios en línea como YouTube, Vimeo y Facebook son plataformas populares que permiten la experiencia de un vídeo esférico interactivo en una pantalla bidimensional común. Por lo tanto, la narrativa en realidad virtual cinematográfica puede verse de forma interactiva con un dispositivo celular. Durante la experiencia, el usuario puede mover la orientación del dispositivo y este mostrará, dentro de su pantalla, partes del video esférico. Mediante la utilización de los sensores en el dispositivo es posible simular que el usuario está viendo un evento como si lo estuviera filmando desde un punto fijo.

Los sujetos con el monitor estarán sentados frente a una pantalla bidimensional y tendrán acceso a un teclado de computador. Previamente recibirán una breve explicación sobre cómo controlar la orientación del video esférico a través de las teclas AwSD (izquierda, arriba, abajo, derecha, respectivamente).

4 La televisión puede ser una experiencia grupal, sin embargo, con el propósito de realizar comparaciones con otros tratamientos en nuestro experimento, se planea como una experiencia individual. 


\section{DISERTACIONES}

\section{ESTUDIOS}

Los sujetos en los procesos de visualización del contenido en medios como el televisivo y el cinematográfico (no 360 ) estarán sentados frente a una pantalla bidimensional, y el encuadre a lo largo de la obra estará determinado por un editor. Detrás de los sujetos, en todos los procesos, se ubicará una cámara que grabará cada sesión. Para la experiencia de la obra con las diferentes tecnologías, se utilizarán cubículos idénticos, completamente aislados de información externa y con una luz ambiental tenue. En cada una de las experiencias, se utilizará la misma silla giratoria.

\section{Derivación de las hipótesis}

Bajo el supuesto de que cada tratamiento o cada tecnología (variable independiente) tenga diferentes impactos en la implicación narrativa (variable dependiente) del espectador. Teniendo en cuenta que la inmersión provista por los visores y la habilidad para determinar lo que se ve acentúa, se especula que la mayor diferencia entre los resultados del MNEQ será registrada entre la RVC y la versión de cine tradicional o la versión para televisión.

H1: MNEQ (Visores) > MNEQ (Cine)

H2: MNEQ (Visores) > MNEQ (Televisión)

Ya que en los tratamientos con móvil y video interactivo en monitor no hay inmersión completa como ocurre con los visores de realidad virtual, se espera que la absorción narrativa sea menor.

H3: MNEQ (Visores) > MNEQ (Monitor)

H4: MNEQ (Visores) > MNEQ (Móvil)

Por igual, se espera una diferencia en los resultados del MNEQ entre las tecnologías interactivas en general (visores, móvil y monitor) y las tecnologías tradicionales (televisión y cine).

Por último, se busca hacer un estudio exploratorio secundario que ayude a profundizar en el conocimiento general relacionado con el uso de la Rvc para la narración de historias ficcionales. Esta parte del estudio estará basada en 2 actividades adicionales: 1) La videograbación de los sujetos en cada tratamiento con la intención de observar su comportamiento en diferentes momentos de la obra y 2 ) en los días posteriores al experimento, en el uso de cuestionarios con preguntas abiertas sobre la experiencia.

\section{Etapas en la realización del experimento}

El proceso de experimentación tendrá el siguiente protocolo: se realizarán 5 sesiones simultáneas de aproximadamente 45 minutos en cubículos de experimentación idénticos. Se seguirá un protocolo homogéneo con todos los participantes de 4 de los procesos o tratamientos desarrollados con anterioridad:

1. Los sujetos comenzarán por leer y firmar un acta de consentimiento.

2. Los sujetos entrarán al cubículo con un asistente, quien les posicionará, dará instrucciones básicas sobre cómo utilizar el equipo basadas en un script y colocará los audífonos.

3. El asistente comenzará la grabación del experimento.

4. Los sujetos verán una obra de 25 minutos. 


\section{DISERTACIONES}

Estudios sobre imágenes en el nuevo ecosistema mediático

ISSN: $1856-9536$

Doi: https://doi.org/10.12804/revistas.urosario.edu.co/disertaciones/a.8252

Volumen 13, Número 2 / Julio-diciembre 2020

Versión PDF para imprimir desde

http://revistas.urosario.edu.co/index.php/disertaciones

5. En el momento justo posterior a la finalización de la obra, los sujetos responderán un cuestionario con el mNEQ. Al finalizar, se les pedirá que no comenten la obra hasta la fecha de finalización del experimento.

6. Al día siguiente, los sujetos recibirán y responderán el segundo cuestionario con preguntas abiertas exploratorias.

7. Los sujetos recibirán una compensación monetaria pequeña.

Buscando incrementar la fiabilidad de los resultados estadísticos, cada experimento contará con un mínimo de 100 sujetos. A los sujetos se les reclutará por medio de publicidad y se les pagará individualmente.

Basado en una encuesta inicial, a los participantes interesados se les realizará una distribución estratificada aleatoria entre los 4 diferentes tratamientos. La estratificación busca garantizar un rango de edad amplio en cada uno de los grupos en el estudio.

\section{Datos y resultados}

1. Estadísticas descriptivas de los participantes en el experimento

2. El MNEQ como instrumento para medir envolvimiento con la narrativa:

a. Estadísticas descriptivas del mNEQ para la experiencia de la obra en cada uno de los tratamientos o grupos experimentales: visores, móvil, computador, televisión y cine.

b. Realizar análisis de congruencia entre las preguntas del cuestionario y considerar la eliminación de algunas de ellas para incrementar la validez del instrumento.

c. Contrastar las estadísticas del tratamiento con visores de realidad virtual con el estudio original en el que se usó el MNEQ.

d. Investigar asociaciones entre los elementos individuales del mNEQ y diferentes tipos de información demográfica (edad, educación, uso de y afinidad por las computadoras, etc.).

3. Análisis comparativo de los 5 grupos:

a. Análisis estadístico comparativo para determinar si las hipótesis son ciertas o no.

b. Análisis de varianza para determinar el efecto del tratamiento en cada uno de los elementos del MNEQ.

c. Análisis de la observación de sujetos en cada una de las condiciones:

- Análisis cualitativo y cuantitativo para determinar el movimiento corporal de los sujetos a lo largo de la experiencia.

- Análisis cualitativo y cuantitativo para determinar la interacción de los sujetos con el contenido a lo largo de la experiencia.

d. Análisis de las preguntas abiertas:

- Análisis cualitativo de las preguntas abiertas realizadas en el día posterior. 


\section{DISERTACIONES}

ESTUDIOS

Estudios sobre imágenes en el nuevo ecosistema mediático

ISSN: $1856-9536$

Doi: https://doi.org/10.12804/revistas.urosario.edu.co/disertaciones/a.8252

Volumen 13, Número 2 / Julio-diciembre 2020

Versión PDF para imprimir desde

http://revistas.urosario.edu.co/index.php/disertaciones

\section{Referencias}

1. Appel, M., Gnambs, T., Richter, T., \& Green, M. C. (2015). The Transportation Scale-Short Form (TS-SF). Media Psychology, 18(2), 243-266. https://doi.org/10.1080/15213269.2014.987400

2. Benítez De Gracia, M. J., \& Herrera Damas, S. (2018). El reportaje inmersivo en video en $360^{\circ}$ en los medios periodísticos españoles. Revista de Comunicación, 17(2), 66-100. https://doi.org/10.26441/RC17.2-2018-A3

3. Burch, N. (1969). Praxis du cinema. París: Gallimard.

4. Busselle, R., \& Bilandzic, H. (2009). Measuring Narrative Engagement. Media Psychology, 12(4), 321-347. https://doi.org/10.1080/15213260903287259

5. Ding, N., Zhou, W., \& Fung, A. Y. H. (2018). Emotional effect of cinematic VR compared with traditional 2D film. Telematics and Informatics, 35(6), 1572-1579. https://doi.org/10.1016/j.tele.2018.04.003

6. Dooley, K. (2017). Storytelling with virtual reality in 360-degrees: a new screen grammar. Studies in Australasian Cinema, 11(3), 161-171. https://doi.org/10.1080/17503175.2017.1387357

7. Green, M. C., Brook, T. C., Kauffman, G. F (2004). Understanding Media Enjoyment: The Role of Transportation Into Narrative Worlds. Communication Theory, 14(4), 311-327. https://doi.org/10.1111/j.1468-2885.2004. tb00317

8. Keshavarz, B., Hecht, H., \& Lawson, B. (2014). Visually Induced Motion Sickness: Causes, Characteristics, and Countermeasures. En K. Hale \& K. Stanney (Ed). Handbook of Virtual Environments, 26, 648-697, CRC Press. https://doi.org/10.1201/b17360-32

9. Kjær, T., Lillelund, C. B., Moth-Poulsen, M., Nilsson, N. C., Nordahl, R., \& Serafin, S. (2017). Can you cut it?: an exploration of the effects of editing in cinematic virtual reality. Proceedings of the 23rd ACM Symposium on Virtual Reality Software and Technology, 1-4. Gothenburg, Sweden: ACM Press. https://doi. org/10.1145/3139131.3139166

10. MacQuarrie, A., \& Steed, A. (2017). Cinematic virtual reality: Evaluating the effect of display type on the viewing experience for panoramic video. IEEE Virtual Reality (VR) 45-54, https://doi.org/10.1109/ VR.2017.7892230

11. Mateer, J. (2017). Directing for Cinematic Virtual Reality: how the traditional film director's craft applies to immersive environments and notions of presence. Journal of Media Practice, 18:1, 14-25. https://doi.org/10.1080/14682753.2017.1305838

12. McArthur, A., Stewart, R., \& Sandler, M. (2017). Sounds too true to be good: diegetic infidelity-the case for sound in virtual reality. Journal of Media Practice, 18(1), 26-40. https://doi.org/10.1080/14682753.2017.1 305840

13. Nielsen, L. T., Moller, M. B., Hartmeyer, S. D., Ljung, T. C. M., Nilsson, N. C., Nordahl, R., \& Serafin, S. (2016). Missing the point: an exploration of how to guide users' attention during cinematic virtual reality. Proceedings of the 22nd ACM Conference on Virtual Reality Software and Technology - VRST '16, 229-232. https://doi.org/10.1145/2993369.2993405 


\section{DISERTACIONES}

\section{ESTUDIOS}

14. Pope, V. C., Dawes, R., Schweiger, F., \& Sheikh, A. (2017). The Geometry of Storytelling: Theatrical Use of Space for 360-degree Videos and Virtual Reality. Proceedings of the 2017 CHI Conference on Human Factors in Computing Systems-CHI '17, 4468-4478. https://doi.org/10.1145/3025453.3025581

15. Richardson, D. C., Griffin, N. K., Zaki, L., Stephenson, A., Yan, J., Curry, T., Devlin, J. T. (2018). Measuring narrative engagement: The heart tells the story. https://doi.org/10.1101/351148

16. Rothe, S., Brunner, H., Buschek, D., \& Hußmann, H. (2018). Spaceline: A Way of Interaction in Cinematic Virtual Reality. Proceedings of the Symposium on Spatial User Interaction-SUI '18, 179-179. https://doi. org/10.1145/3267782.3274675

17. Serrano, A., Sitzmann, V., Ruiz-Borau, J., Wetzstein, G., Gutierrez, D., \& Masia, B. (2017). Movie Editing and Cognitive Event Segmentation in Virtual Reality Video. ACM Transactions on Graphics, 36(4), 1-12. https:// doi.org/10.1145/3072959.3073668

18. Sutherland, I. E. (1968). A head-mounted three dimensional display. Proceedings of the December 9-11, 1968, fall joint computer conference, part I on - AFIPS '68 (Fall, part I), 757. https://doi. org/10.1145/1476589.1476686

19. Truffaut, F. (5a Ed., 2010). El cine según Hitchcock. Madrid: Editorial Alianza.

20. Vosmeer, M., \& Schouten, B. (2017). Project Orpheus A Research Study into $360^{\circ}$ Cinematic VR. Proceedings of the 2017 ACM International Conference on Interactive Experiences for TV and Online Video - TVX '17 (pp. 85-90). Hilversum, The Netherlands: ACM Press. https://doi.org/10.1145/3077548.3077559

21. Zunzunegui, S. (1998). Pensar la imagen. Madrid: Cátedra. 